\title{
Frontières
}

\section{GRÜN, Anselm, L'onction des malades : tendresse et réconfort, traduit de l'allemand par Annick Lalucq, Paris, Médiaspaul, 2003, 54 p.}

\section{Anne Létourneau}

Volume 17, numéro 1, automne 2004

URI : https://id.erudit.org/iderudit/1073618ar

DOI : https://doi.org/10.7202/1073618ar

Aller au sommaire du numéro

Éditeur(s)

Université du Québec à Montréal

ISSN

1180-3479 (imprimé)

1916-0976 (numérique)

Découvrir la revue

Citer ce compte rendu

Létourneau, A. (2004). Compte rendu de [GRÜN, Anselm, L'onction des malades : tendresse et réconfort, traduit de l'allemand par Annick Lalucq, Paris, Médiaspaul, 2003, 54 p.] Frontières, 17(1), 97-98.

https://doi.org/10.7202/1073618ar d'utilisation que vous pouvez consulter en ligne.

https://apropos.erudit.org/fr/usagers/politique-dutilisation/ 
GRÜN, Anselm

\section{L'onction des malades: tendresse et réconfort traduit de l'allemand par Annick Lalucq Paris, Médiaspaul, 2003, 54 p.}

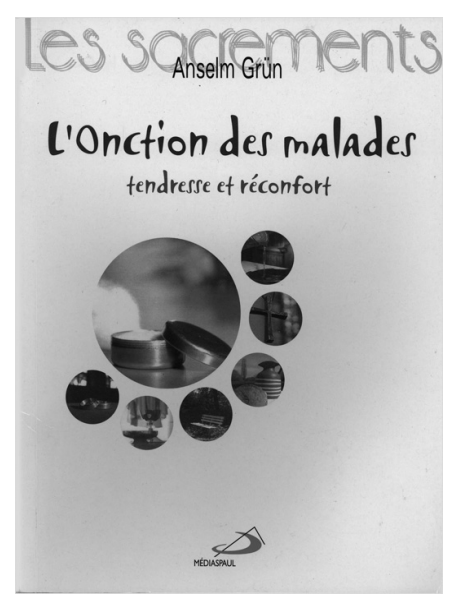

Par le biais de la plaquette intitulée L'onction des malades: tendresse et réconfort, Anselm Grün, moine bénédictin ayant beaucoup écrit sur la spiritualité, propose une brève réflexion sur le sacrement de l'onction des malades. II cherche à mettre en lumière l'attitude spécifiquement "chrétienne» face à la maladie et à la mort, une attitude tissée de compassion et de sollicitude, ainsi qu'à réaffirmer le lieu de rencontre avec le Christ que constitue l'onction des malades.

Dans la première partie de son opuscule, Grün s'intéresse d'abord aux passages néotestamentaires reliés à l'onction des malades (Matthieu 10, 8, Jacques 5, 14-15, Actes 3, 16 et Marc 6, 13), puis aux textes des Pères de l'Église et enfin à la déclaration du concile de Trente qui reconnut en Marc 16,3 la pierre d'assise du sacrement. II s'interroge ensuite sur la riche symbolique de I'huile, tout en lançant l'avertissement suivant: I'onction des malades n'a rien de magique, c'est le pouvoir de la prière qui est ici en jeu (p. 10).

À la suite de l'exploration des fondements textuel, symbolique et spirituel de l'onction des malades, l'auteur s'intéresse brièvement à I'histoire de ce sacrement qui est avant tout celle de son administration. L'usage des saintes huiles fut instauré afin de lutter contre les "pratiques superstitieuses et païennes auxquelles on avait recours pour conjurer la maladie» (p. 12). Les saintes huiles furent consacrées par les évêques dès le III siècle, mais ces derniers perdirent à moult reprises l'administration exclusive de ce sacrement. Aujourd'hui, comme le souligne Grün, se pose toujours la question des personnes les plus aptes à l'administration de l'onction. L'auteur propose, pour sa part, que I'huile demeure consacrée par les évêques et que le sacrement soit administré sous son autorité, mais par les proches ou les aumôniers des hôpitaux. Ainsi, «[...] il ne s'agirait pas seulement d'un acte de piété privé, mais d'une démarche d'Église ayant lieu à la demande et avec la bénédiction de l'évêque» (p. 16). II est regrettable que cette prise de position de l'auteur trouve son seul ancrage dans la lettre de Jacques et les propos du pape Innocent $1^{\mathrm{e}}$, sans égards aux réalités des croyants d'aujourd'hui et par là à la nécessaire réactualisation d'un tel rite.

Autre aspect intéressant de I'histoire du sacrement noté par Grün que celui de sa nature même. En effet, alors qu'à l'époque carolingienne, ce sacrement prend désormais le nom d' «extrême-onction " par son association étroite avec la mort, cette orientation est mise de côté avec le Concile 
Vatican II, qui préfère la rediriger vers la maladie (p. 14-15). Grün discerne, fort judicieusement, dans ce changement de cap, l'empreinte d'une société tout aussi changeante, dont la tendance première est la dissimulation du mourir, et affirme sa préférence pour une position du juste milieu entre "onction des malades" et "extrême-onction", rappelant par ailleurs que la «maladie est toujours messagère de mort» (p. 15).

Puis, Anselm Grün considère I'onction des malades dans sa nature de rite de passage vers la maladie, vers la mort. La maladie constituant une expérience vive de la fragilité de l'existence humaine, un «ébranlement existentiel» (p.18), le rite de l'onction des malades vient permettre la rencontre du croyant non seulement avec le "Christ souffrant", dont la passion n'est pas sans rappeler l'évolution de la maladie, mais aussi avec le "Christ médecin" qui fait acte de présence et donc de compassion à travers le sacrement, par les gestes du prêtre, et à qui le malade doit s'abandonner, dans l'espoir d'une guérison physique, dans la certitude d'une guérison spirituelle (p. 20).

Il est ensuite question de la dimension féminine, maternelle, de Dieu, qui se manifeste à travers I'onction des malades. Se référant au Nouveau Testament, l'auteur rappelle que «depuis toujours, I'Église a lié la mort au visage maternel de Dieu » (p. 21). Ainsi, la féminité se trouve-t-elle exprimée dans la douceur de l'huile avec laquelle le prêtre oint le malade alors que l'image de la mère se trouve au carrefour de la mort et de la renaissance. Cette idée d'un caractère maternel de Dieu est certes intéressante, mais n'échappe pas à un certain "stéréotype" de l'essence maternelle, modèle divin du féminin pouvant devenir «idéeprison" pour les femmes.

Dans la seconde partie de l'ouvrage, Grün s'intéresse à chacun des éléments importants du rite. Citant Greshake, il y définit l'onction des malades comme un "[...] renouvellement du baptême dans une situation où l'être humain se voit confronté aux limites de sa vie, sans être en mesure de la contrôler luimême" (p. 23; Greshake, p. 422). Sans présenter de manière exhaustive chacun des éléments du rite sur lesquels se penche Grün, il est intéressant de remarquer l'importance accordée aux proches dans son déroulement. De même que les disciples de Jésus-Christ guérissaient en son nom et par sa force, lors du sacrement, les proches participent à la prière pour le malade, créent une atmosphère de tendresse, d'amour, autour de lui. II y a "sacralisation de l'espace» (p. 23) par les pairs au nom du Christ, le sacré étant la source par excellence de la guérison. Cette présence humaine se révèle nécessaire tout au long du rite, dans l'interprétation pratique qu'en fait Grün. En effet, c'est non seulement au moment des prières, mais aussi lors de l'imposition des mains que la participation des proches est requise. Alors, à travers I'onction d'huile se trouvent véhiculées les idées de résistance puis de réconciliation face à la maladie et face à l'amour, christique et humain (p. 28-30).

Quittant les implications pratiques et symboliques du rite, Grün justifie l'importance de l'onction des malades par deux arguments profondément enracinés dans le sol chrétien. Tout d'abord, il considère la guérison de l'âme comme un commandement auquel le chrétien doit répondre, une vocation de celui-ci. Aussi, selon Grün, I'onction des malades vient mettre en lumière la possibilité d'un vécu de la maladie comme un défi spirituel. En effet, la maladie est l'espace-temps par excellence suscitant les questions les plus existentielles; il s'agit d'une "chance pour réfléchir sur [s]a vie et en revoir les points essentiels" (p. 41). Confrontation inévitable avec sa finitude, la maladie questionne et invite à se pencher sur soimême, mais aussi sur l'Autre, Dieu.

L'auteur aborde ensuite le sujet "les écrivains et la maladie", explorant les différentes attitudes de ceux-ci face à leur souffrance. Alors que certains acceptent leur maladie au nom de la souffrance qui fut celle du Christ, d'autres se rebellent contre elle ou s'en tiennent à distance, afin d'éviter sa suprématie. Cette digression, bien qu'intéressante, n'alimente pas vraiment le propos de l'auteur sur le sacrement des malades, mais pose plutôt la question des différents rapports de l'humain à la souffrance.

Finalement, Grün affirme la nécessité de l'onction des malades en la définissant comme un acte de maîtrise spirituelle de la maladie en ce qu'à travers le cheminement de l'individu et parallèlement à travers le rite lui-même, il y a abandon progressif à Dieu, à son amour et à sa tendresse; alors la maladie devient l'acte même de prière vers et avec lui, "participation à la passion du Christ» (p. 49). Le rite vient donner sens à la souffrance, à la maladie, il est rencontre avec le Christ.
Grün, il est certain, aurait pu faire preuve de plus de créativité afin d'adapter le rite de l'onction des malades aux réalités des chrétiens d'aujourd'hui. Néanmoins, son interprétation du sacrement, tout en demeurant très orthodoxe, souligne de très belle façon la coïncidence symbolique de l'amour du Christ ainsi que la sollicitude des proches pour l'individu en souffrance, dont l'expression est constante dans le rite par le biais de la prière, du toucher, etc. Cette mise en lumière de la "participationmanifestation" du sacré de et par I'humain pour son proche malade est une force incontestable de la réflexion de Grün.

Anne Létourneau 